\title{
PERUBAHAN KANDUNGAN KARBON DAN NILAI EKONOMINYA PADA KONVERSI HUTAN RAWA GAMBUT MENJADI HUTAN TANAMAN INDUSTRI PULP
}

\author{
The Change of Carbon Stock and It's Economic Value on Peatswamp Forest Conversion \\ towards Pulpwood Industrial Plantation Forest
}

\author{
Yanto Rochmayanto ${ }^{1)}$, Dudung Darusman ${ }^{2)}$ dan/and Teddy Rusolono ${ }^{3)}$ \\ ${ }^{1)}$ Balai Penelitian Hutan Penghasil Serat, Badan Litbang Kehutanan. Jl. Raya Bangkinang-Kuok Km 9 \\ Bangkinang, Riau (28463), Telp. (0762) 7000122, Fax. (0762) 7000122 \\ e-mail : yrochmayanto@yahoo.co.id \\ ${ }^{2)}$ Departemen Manajemen Hutan, Fakultas Kehutanan IPB, Bogor \\ Kampus Dramaga IPB, Bogor, HP: 08129063201, e-mail: ddarusman@yahoo.com \\ ${ }^{3)}$ Departemen Manajemen Hutan, Fakultas Kehutanan IPB, Bogor \\ Kampus Dramaga IPB, Bogor, HP: 08128257345, e-mail: trusolono@gmail.com.
}

Naskah masuk : 6 November 2009 ; Naskah diterima : 24 Februari 2010

\begin{abstract}
Peatswamp forests are important terestrial carbon $(C)$ stock in the world. At the present time, the existence of peatswamp forests progressively threatened by pulpwood industrial plantation forests conversion. Therefore, research about change of $C$ stock and its economic value are important. The objectives of the research are: (1) to know the change of C stock on peatswamp forest conversion towards pulpwood industrial plantation forest, (2) to get the carbon economic value of peatswamp forest and pulpwood industrial plantation forest, and (3) to evaluate the the role of pulpwood industrial plantation forest on peatland within supporting climate change mitigation. $C$ stocks are counted by allometric equation, and C economics by the economic acceptance of REDD (Reducing Emission from Deforestation and Forest Degradation) project approach. The result showed that conversion from logged over and secondary forest causing decrease of C stocks of 103.53 and 61.02 ton/ha/year, while conversion from degraded forest causing increase of C stocks of 22.47 ton/ha/year. Economic value of pulpwood industrial plantation forest was Rp 15.56 million/ha. REDD project on pulpwood industrial plantation forest from degraded land causing increase of NPV of 20.21\% and 51,13\% for compensation prices US\$ 9 and $12 / t \mathrm{CO}_{2}-$ e. REDD project on logged over forest gave the higher economic value than pulpwood plantation at compensation prices US\$ 9 and $12 / \mathrm{tCO}_{2}-e$ (both on conservation and preservation logging scenario). Thereby this research shows an evidence that carbon of infact peatswamp forest is more valuable economically than pulpwood industrial plantation forest.
\end{abstract}

Key words : carbon, peat swamp forest, pulpwood industrial plantation forest, conversion, REDD

\begin{abstract}
ABSTRAK
Hutan gambut merupakan cadangan karbon yang penting. Saat ini keberadaan hutan rawa gambut semakin terancam oleh ekpansi HTI pulp, sehingga penelitian tentang perubahan kandungan C dan nilai ekonominya penting dilakukan. Penelitian ini bertujuan untuk : (1) mengetahui perubahan simpanan C pada konversi hutan rawa gambut menjadi HTI pulp, dan (2) mendapatkan nilai ekonomi karbon pada hutan alam gambut dan hutan tanaman industri pulp. Kandungan $\mathrm{C}$ dikuantifikasi dengan persamaan alometrik, dan nilai ekonomi $\mathrm{C}$ dihitung dengan pendekatan penerimaan ekonomi proyek REDD. Hasil penelitian menunjukkan bahwa konversi hutan gambut bekas tebangan dan sekunder menyebabkan penurunan kandungan $C$ vegetasi masing-masing sebesar 103,53 ton/ha/th dan 61,02 ton/ha/th. Sedangkan konversi pada hutan gambut terdegradasi menyebabkan peningkatan kandungan karbon
\end{abstract}


vegetasi sebesar 22,47 ton/ha/th. Nilai ekonomi HTI pulp diperoleh sebesar Rp 15,56 juta/ha. Proyek REDD HTI pulp dari hutan terdegradasi menyebabkan peningkatan nilai ekonomi sebesar 20,21\% dan 51,13\% untuk harga satuan kompensasi US\$ 9 dan 12/tCO ${ }_{2}$-e. Proyek REDD pada hutan gambut bekas tebangan memiliki nilai ekonomi yang lebih tinggi dari HTI pulp pada harga satuan kompensasi US\$ 9.00/tCO PHPL. Dengan demikian, penelitian ini menunjukkan bahwa bahwa karbon dari hutan gambut lebih bernilai ekonomi dibandingkan dengan pengusahaan HTI pulp.

Kata kunci : karbon, hutan rawa gambut, hutan tanaman industri, konversi, REDD

\section{PENDAHULUAN}

Hutan gambut (atau hutan rawa gambut) merupakan bentuk simpanan karbon yang penting dalam siklus karbon global. Sebagian besar karbon tanah di dunia ditemukan dalam lahan gambut dan 20\%-nya berada pada areal gambut tropika (Anshari dan Armiyarsih, 2005). Lahan gambut tropis luasnya mencapai 40 juta hektar, $50 \%$ diantaranya terdapat di Indonesia yang tersebar di Sumatera, Kalimantan dan Papua (Murdiyarso et al., 2004).

Lahan gambut jika dikelola dengan benar dapat meningkatkan kemampuannya dalam menyimpan karbon. Namun, apabila hutan gambut dikonversi menjadi bentuk penggunaan lain atau mengalami gangguan akan berubah menjadi sumber emisi karbon yang cukup potensial. Saat ini, sejumlah besar lahan gambut tropika mengalami degradasi akibat pembalakan, konversi dan kebakaran (Anshari dan Armiyarsih, 2005). Wahyunto dkk. (2005) menyatakan bahwa kandungan karbon tanah gambut di Riau turun sebesar 2.246,18 juta ton selama 12 tahun (1990-2002). Penurunan ini disebabkan oleh penurunan ketebalan gambut akibat konversi untuk perkebunan kelapa sawit dan HTI. Proses konversi dapat menyebabkan kehilangan air oleh sistem drainase, pemadatan gambut, dekomposisi yang lebih cepat dan meningkatkan resiko kebakaran.

Kebutuhan lahan untuk HTI pulp terus bertambah karena konsumsi kertas dunia meningkat. Penggunaan lahan mineral untuk HTI pulp mengalami kompetisi dengan perkebunan sawit, sehingga lahan gambut menjadi alternatif perluasan HTI. Menurut Hooijer et al., 2006 terdapat sekitar 27\% lahan HTI dan perkebunan sawit di Indonesia berada di lahan gambut, dan $54,8 \%$ HTI yang ada menggunakan lahan gambut. Kendati pembangunan HTI pulp memberikan kontribusi terhadap peningkatan ekonomi (Departemen Kehutanan, 2008), namun diduga penerimaan ekonomi dari pembangunan HTI pulp memiliki korelasi dengan degradasi hutan.

Dalam rangka menjawab kebutuhan kebijakan alternatif, diperlukan kajian pola penggunaan/pemanfaatan lain yang mampu memberikan manfaat ekonomi tinggi tanpa menyebabkan degradasi. Alternatif kebijakan yang saat ini potensial adalah perdagangan karbon antara lain dengan REDD (Reducing Emission from Deforestation and Degradation), yaitu sebuah mekanisme pembayaran kompensasi atas penghindaran pemanfaatan lahan yang menyebabkan deforestasi dan degradasi sehingga mampu menahan emisi karbon (Ministry of Forestry, 2008). Namun demikian, terdapat beberapa masalah terkait dengan perdagangan karbon diantaranya adalah belum tersedianya data dan informasi secara rinci tentang dinamika kandungan karbon pada konversi hutan alam gambut menjadi HTI pulp, belum adanya data potensi nilai ekonomi dari karbon hutan alam dan HTI pulp, serta belum diketahuinya relevansi penghindaran konversi hutan rawa gambut menjadi HTI pulp untuk dapat dimasukkan ke dalam mekanisme REDD.

Berdasarkan uraian tersebut, penelitian ini bertujuan untuk : (1) memperoleh informasi dinamika/perubahan simpanan karbon pada konversi hutan alam gambut menjadi hutan tanaman penghasil pulp, dan (2) mendapatkan nilai ekonomi karbon pada hutan alam gambut dan hutan tanaman industri pulp. Hasil penelitian ini diharapkan bermanfaat bagi pemerintah (Kementerian Kehutanan), penggiat mitigasi dan adaptasi perubahan iklim, para praktisi kehutanan dan maupun akademisi yang berhubungan dengan bidang kehutanan. Melalui data dan analisis penelitian ini diharapkan juga dapat menambah referensi untuk pengambilan 
keputusan alokasi hutan alam gambut yang sesuai kebutuhan pembangunan nasional dan relevan dengan upaya mitigasi perubahan iklim.

\section{METODE PENELITIAN}

\section{A. Lokasi dan Waktu Penelitian}

Penelitian ini dilakukan di areal konsesi HTI PT Riau Andalan Pulp and Paper (PT. RAPP) Kabupaten Pelalawan, Riau. Penelitian dilakukan pada bulan Maret - Juni 2009.

\section{B. Ruang Lingkup Penelitian}

Penelitian ini dilakukan pada lahan gambut. Gas Rumah Kaca (GRK) yang dikuantifikasi dibatasi pada unsur karbon. GRK yang berpengaruh terhadap pemanasan global terdiri atas banyak jenis unsur dan senyawa. Namun karena vegetasi memiliki peran besar dalam menyerap $\mathrm{CO}_{2}$ dari atmosfer dan melakukan simpanan karbon (dalam bentuk biomassa, dan 50\%-nya adalah karbon (Murray, 2004; Rahmat dkk., 2007b), maka fokus kajian dibatasi pada perhitungan simpanan karbon vegetasi.

Kajian meliputi aspek perhitungan simpanan karbon vegetasi hutan rawa gambut dalam beberapa kondisi dan pada kawasan HTI pulp lahan gambut dalam berbagai kelas umur. Kondisi hutan alam gambut dibedakan pada 3 kategori, yaitu : hutan bekas tebangan (logged over forest), hutan sekunder (secondary forest) dan hutan terdegradasi (degraded forest). Adapun kelas umur tanaman pada HTI pulp terdiri atas umur 1 sampai 5 tahun.

Hutan rawa gambut bekas tebangan yang dimaksud adalah hutan rawa gambut bekas aktivitas penebangan (oleh HPH atau lainnya) yang masih memiliki potensi vegetasi (growing stock) tinggi dan masih menunjukkan ciri-ciri hutan primer. Hutan rawa gambut sekunder adalah hutan rawa gambut bekas tebangan yang telah mengalami tekanan penggunaan lebih lanjut sehingga potensinya menurun dan telah menunjukkan adanya jenis-jenis pionir yang berbeda dengan jenis alami hutan rawa sebelumnya. Adapun hutan gambut terdegradasi yang dimaksud adalah hutan rawa gambut sekunder yang telah mengalami tekanan lebih lanjut (pembalakan, tebas bakar, perambahan, dan lain-lain) sehingga potensi vegetasinya sangat sedikit atau tidak ada sama sekali. Secara skematis, definisi operasional hutan rawa gambut pada 3 kondisi ini diilustrasikan pada Gambar 1.

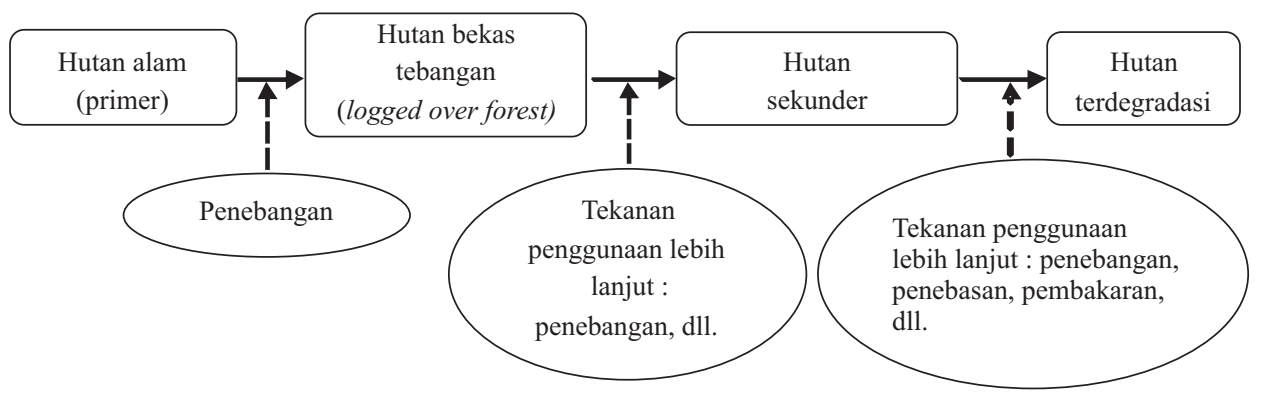

Gambar(Figure) 1. Skema dinamik pembentukan kondisi hutan rawa gambut (Dynamic scheme of peatswamp forestformation)

\section{Prosedur Penelitian}

\section{Perhitungan Kapasitas Serapan Karbon}

a. Membuat plot contoh pengukuran 20 x $50 \mathrm{~m}$ pada setiap jenis penutupan lahan gambut (Hairiah dan Rahayu, 2007). Jenis penutupan lahan tersebut terdiri atas :

(1) Hutan alam gambut dalam 3 kondisi : hutan alam gambut bekas tebangan, sekunder dan terdegradasi

(2) HTI di lahan gambut pada kelas umur 1 sampai 5 tahun.

Jumlah plot untuk masing-masing jenis penutupan lahan adalah 3 plot dengan metode sistematik awal acak. Jarak antar plot adalah $50 \mathrm{~m}$ diukur dari batas luar plot. 
b. Pengukuran diameter dilakukan pada batang setinggi dada $(d b h)$ dilakukan pada pohon dengan diameter minimal $5 \mathrm{~cm}$.

c. Pengolahan data dilakukan dengan menghitung biomasa dengan persamaan alometrik sebagai berikut.

(1) Biomasa vegetasi hutan alam gambut di atas permukaan tanah (above-ground biomass) dihitung menggunakan persamaan allometrik menurut Murdiyarso dkk. (2004) :

$$
\mathrm{W}=\rho 0,19 \mathrm{D}^{2,37}
$$

Keterangan: $\mathrm{W}$ : bobot kering $(\mathrm{kg})$

$\mathrm{D}$ : diameter pohon $(\mathrm{cm})$

$\rho:$ BJ kayu $\left(\mathrm{g} / \mathrm{cm}^{3}\right)$

Biomasa akar (below-ground biomass) diestimasi menggunakan nisbah tajuk akar (root to shoot ratio, $R / S$ ratio) yaitu 0.25 (Brown, 1994; Istomo, 2002; IPCC, 2006).

(2) Persamaan allometrik untuk menduga biomasa tegakan Acacia crassicarpa (atas dan bawah permukaan) menggunakan persamaan allometrik (Rahmat dkk., 2007a):

$$
\mathrm{W}=0,0267 \mathrm{D}^{2,8912}
$$

(3) Menjumlahkan biomasa semua pohon yang ada pada suatu lahan, sehingga diperoleh total biomasa pohon per lahan (kg/luasan lahan).

d. Estimasi jumlah $\mathrm{C}$ tersimpan per lahan dihitung dengan persamaan IPCC (2006), yaitu:

$$
\mathrm{C}=\text { Biomasa }(\mathrm{kg}) \times 0,5
$$

e. Estimasi serapan $\mathrm{CO}_{2}$ dilakukan dengan mengalikan $\mathrm{C}$ terhadap faktor konversi ke $\mathrm{CO}_{2}$ sebesar 44/12 (IPCC, 2006).

f. Perhitungan perubahan kandungan karbon pada luasan areal tertentu dilakukan dengan pendekatan atas dasar perbedaan stock (stock different method) (IPCC, 2006). Formula matematis metode tersebut dapat dinotasikan sebagai berikut:

$$
\Delta \mathrm{C}_{L U i}=\mathrm{C}_{A^{-}} \mathrm{C}_{B}
$$

Keterangan :

$\Delta \mathrm{C}_{L U i}$ : perubahan kandungan karbon pada penggunaan lahan tertentu (ton/ha)

$\mathrm{C}_{A}$ : kandungan karbon pada peng-gunaan lahan sebelum konversi (ton/ha) $\begin{array}{cl}\mathrm{C}_{B}: & \text { kandungan karbon pada peng-gunaan } \\ & \text { lahan sesudah konversi (ton/ha) }\end{array}$

\section{Perhitungan Nilai Ekonomi Karbon}

Nilai ekonomi karbon dihitung dengan pendekatan nilai ekonomi dari proyek REDD pada periode proyek (life time) 5 tahun. Pembayaran proyek REDD dilakukan dengan mekanisme ex-ante full credit (pembayaran penuh pada awal proyek). Harga karbon menggunakan harga hipotetis menurut Pirard (2005) yaitu US\$6, US\$9 dan US\$12/ton $\mathrm{CO}_{2}$-e. Adapun nilai ekonomi HTI didekati dengan analisis ekonomi dengan batasan aktivitas persiapan pembangunan HTI sampai penjualan kayu ke industri. Rotasi tebang HTI adalah 5 tahun, sehingga terjadi siklus biomasa vegetasi pada suatu lokasi (site) selama 5 tahun. Suku bunga yang digunakan adalah suku bunga riil, yaitu tingkat suku bunga pasar yang telah dikoreksi oleh inflasi $(6,28 \%)$.

Prosedur penilaian ekonomi mengikuti tahapan sebagai berikut:

1. Melakukan analisis ekonomi pembangunan dan pengelolaan HTI pulp. Hasil analisis ini digunakan untuk menentukan besarnya biaya oportunitas, biaya transaksi dan biaya total proyek REDD.

2. Apabila kandungan $\mathrm{C}$ HTI $>$ kandungan $\mathrm{C}$ hutan alam, kemudian dilakukan :

a. Analisis ekonomi proyek REDD dari HTI pulp

b. Analisis komparasi nilai ekonomi HTI pulp murni dengan nilai ekonomi proyek REDD dari HTI pulp.

3. Apabila kandungan $\mathrm{C}$ HTI $<$ kandungan $\mathrm{C}$ hutan alam, kemudian dilakukan :

a. Analisis ekonomi proyek REDD dari hutan alam gambut

b. Analisis komparasi nilai ekonomi HTI pulp murni dengan nilai ekonomi proyek REDD dari hutan alam.

Indikator investasi yang digunakan untuk mengukur status kelayakan aktivitas ekonomi dari pola penggunaan lahan hutan gambut adalah : NPV (Net Present Value), BCR (Benefit Cost Ratio) dan IRR (Internal Rate of Return). Struktur biaya proyek REDD terdiri atas biaya oportunitas dan biaya transaksi. Secara matematis formula menghitung biaya dan 
penerimaan REDD (Agus et al., 2007; Ginoga \& Lugina, 2007) dinyatakan sebagai berikut:

Biaya oportunitas $\left(\mathrm{Rp} / \mathrm{tCO}_{2}\right)=(\mathrm{NPV} / \mathrm{ha}) /$ (Emisi $\mathrm{CO}_{2} /$ ha)

Biaya transaksi $\left(\mathrm{Rp} / \mathrm{tCO}_{2}\right)=39,2 \% \times$ Total Biaya

Total Biaya $\left(\mathrm{Rp} / \mathrm{tCO}_{2}\right)=$ Biaya oportunitas + biaya transaksi

Penerimaan $\left(\mathrm{Rp} / \mathrm{tCO}_{2}\right)=$ Harga satuan kompensasi $\mathrm{x}$ emisi $\mathrm{Co}_{2}$

\section{HASIL DAN PEMBAHASAN}

\section{A. Perubahan Stok Karbon Hutan Alam dan HTI Pulp}

\section{Hutan Rawa Gambut}

Kapasitas simpanan $\mathrm{C}$ pada tiga kondisi hutan alam menunjukkan perbedaan yang nyata. Hutan alam terdegradasi tidak memiliki kandungan karbon vegetasi sebab tidak ditemukan vegetasi berdiameter $5 \mathrm{~cm}$ atau lebih. Vegetasi didominasi oleh rumput dan semak.

Simpanan C terbanyak di hutan bekas tebangan berada pada pohon-pohon dengan kelas diameter $>75 \mathrm{~cm}$. Walaupun jumlah pohonnya lebih sedikit, kandungan biomasanya mencapai 81,22 ton/ha sehingga kandungan karbonnya 40,61 ton/ha. Adapun simpanan C terkecil adalah vegetasi pada kelas diameter 55-65 $\mathrm{cm}$ dengan jumlah 4,18 ton $\mathrm{C} /$ ha. Pada hutan sekunder, kandungan $\mathrm{C}$ terbanyak tidak berada pada kelas diameter terbesar tetapi pada kelas diameter 15$25 \mathrm{~cm}$, yaitu 18,23 ton/ha. Adapun kandungan C terkecilnya dijumpai pada kelas diameter 65-75 cm sebesar nol karena pada ketiga plot sampel tidak dijumpai vegetasi dengan diameter tersebut (Gambar 2).

Total kandungan karbon di hutan alam gambut pada lokasi penelitian (Pelalawan, Riau) sebesar 126,01 ton/ha yang terdapat di hutan bekas tebangan dan 83,49 ton/ha di hutan sekunder. Jumlah tersebut berbeda dengan hutan gambut di Kalimantan Tengah sebesar 268,18 ton C/ha (Jaya et al., 2007). Kandungan $\mathrm{C}$ vegetasi atas permukaan di hutan primer Kamerun (Afrika) 155 ton $\mathrm{C} / \mathrm{ha}$, di hutan sekunder Nicaragua (Amerika) 91,5 ton $\mathrm{C} /$ ha dan di Malaysia pada hutan rawa 110 ton C/ha (Brown, 1994). Kandungan C di Asia Selatan dan Tenggara sebesar 77 ton/ha (FAO, 2006) dan di

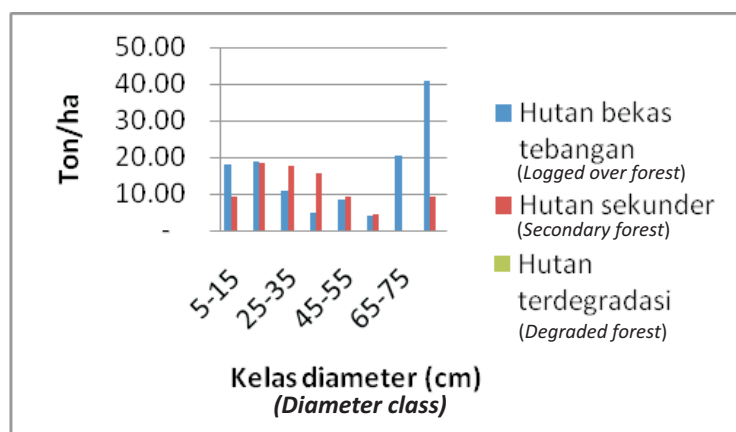

Gambar(Figure)2. Sebaran kandungan karbon menurut kelas diameter pada hutan bekas tebangan dan hutan sekunder (Distribution of carbon stocks based on diameter class at logged over forest and secondary forest)

hutan musim Asia sebesar 145 ton C/ha (IPCC, 2006).

Variasi berbagai laporan tersebut diduga akibat perbedaan metode dan perbedaan tipe hutan gambut. Metode perhitungan karbon secara destruktif dan non destruktif akan memberikan hasil yang berbeda karena metode non destruktif menggunakan model penduga untuk menghitung kandungan karbon. Aplikasi model penduga akan menimbulkan bias pada hasil kalkulasi yang besarnya tergantung kepada nilai $\mathrm{R}^{2}$ dan faktor kesesuaian model dengan lokasi penelitian. Metode ini juga berkaitan dengan instrumen pendugaan yang dilakukan. Pendugaan karbon yang dilakukan berdasarkan pengukuran dimensi pohon akan memberikan hasil yang berbeda dengan hasil pendugaan berdasarkan interpretasi penginderaan jauh. Ekosistem hutan yang menjadi obyek penelitian juga memberikan andil besar dalam variasi hasil pengukuran. Variasi akibat perbedaan tipe hutan gambut dipengaruhi oleh perbedaan jenis vegetasi penyusun ekosistem, ketebalan dan kematangan gambut.

\section{HTI Lahan Gambut Acacia crassicarpa}

HTI memiliki pola sebaran vegetasi yang berbeda dengan hutan alam. Perbedaan tersebut meliputi: jenis tanaman monokultur, variasi struktur vertikal dan horizontal tegakan tunggal. Pengaturan dan kompartemenisasi tanaman dan tebangan menyebabkan sistem kawasan menjadi berpola mozaik. Hasil pengukuran menggambarkan kapasitas simpanan C HTI pulp disajikan pada Gambar 2. Jumlah pohon per 
hektar akan semakin berkurang seiring dengan pertambahan umur tegakan. Pengurangan jumlah pohon ini disebabkan oleh mortalitas akibat angin (tumbang). Pola penurunan jumlah pohon per hektar ini berbanding terbalik dengan pola perkembangan diameter, biomasa dan kandungan C. Ketiga parameter ini semakin meningkat seiring dengan pertambahan umur tegakan. Pada umur satu tahun tegakan Acacia crassicarpa memiliki kandungan $\mathrm{C}$ sebesar 4,59 ton/ha, meningkat terus sampai 39.51 ton/ha pada tahun kelima.

Hasil ini lebih rendah dibandingkan laporan Rahmat dkk. (2007b) pada jenis yang sama di PT SBA, yang pada umur 2 dan 3 tahun mencapai 29,92 ton/ha dan 48,35 ton/ha. Hal ini diduga akibat perbedaan kualitas tempat tumbuh (kesuburan tanah), genetika bahan tanaman atau tindakan silvikultur yang diberikan.

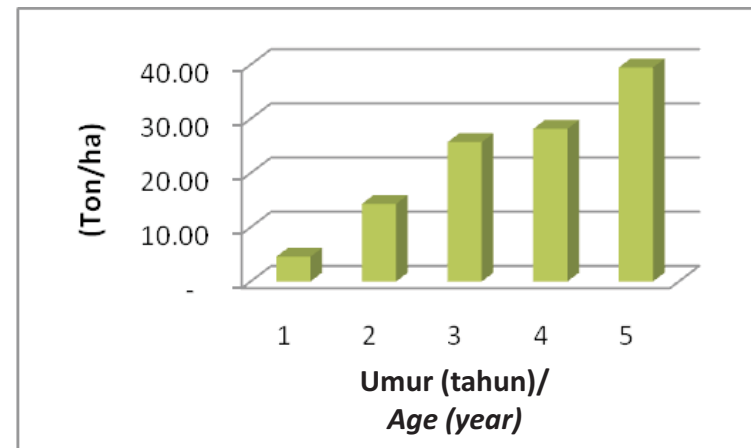

Gambar(Figure)3. Perubahan kandungan karbon tanaman HTI Acacia crassicarpa (Changes of carbon stocks at industrial plantation forest of Acacia crassicarpa)

\section{Perubahan Kandungan Karbon pada Perubahan Fungsi Hutan}

Pada skala per hektar, perubahan hutan gambut bekas tebangan menjadi HTI pulp menyebabkan penurunan kandungan $\mathrm{C}$ sebesar 121,42 ton pada tahun pertama dan 86,50 ton/ha pada tahun ke-5. Rata-rata emisi tahunan yang timbul akibat konversi menjadi HTI pulp pada setiap petak hutan gambut adalah 103,53 ton $\mathrm{C} /$ ha/th. Perubahan hutan sekunder menjadi HTI pulp menyebabkan penurunan kandungan $\mathrm{C}$ sebesar 78,90 ton/ha pada tahun pertama dan 43,98 ton/ha pada tahun ke-5. Rata-rata emisi tahunan pada setiap petak hutan gambut sekunder yang dikonversi menjadi HTI pulp sebesar 61,02 ton $\mathrm{C} / \mathrm{ha} / \mathrm{th}$. Hal ini menunjukkan bahwa perubahan hutan gambut bekas tebangan tidak sesuai dengan prinsip additionality untuk mitigasi perubahan iklim. Sebab konversi hutan rawa gambut bekas tebangan dan sekunder menjadi HTI pulp menyebabkan penurunan kandungan karbon, sementara mitigasi perubahan iklim yang diakui dan berpotensi memperoleh kompensasi adalah ketika perubahan penggunaan lahan memberikan dampak peningkatan kandungan karbon. Namun sebaliknya, konversi hutan alam terdegradasi menjadi HTI pulp menunjukkan penambahan kandungan $\mathrm{C}$ sebesar 39,51 ton/ha, atau rata-rata 22,47 ton $\mathrm{C} / \mathrm{ha} / \mathrm{th}$. Situasi ini menggambarkan tercapainya prinsip additionality sehingga dapat diajukan pada proyek REDD.

Perubahan kandungan $\mathrm{C}$ dalam satuan wilayah dihitung pada satuan unit pengelolaan HTI, yaitu 51.215 ha. Kalkulasi dilakukan dengan menggambarkan sebaran umur tegakan HTI sebagai hutan normal, sehingga setiap kelas umur memiliki luasan yang sama (10.243 ha). Perubahan HTI pulp dari hutan bekas tebangan pada skala unit pengelolaan menyebabkan penurunan kandungan $\mathrm{C}$ sebesar 5,30 juta ton (19,44 juta ton $\mathrm{CO}_{2}$-e). Apabila perubahan dilakukan dari hutan sekunder, penurunan kandungan $\mathrm{C}$ teridentifikasi sebesar 3,13 juta ton $\left(11,46\right.$ juta ton $\left.\mathrm{CO}_{2}-\mathrm{e}\right)$.

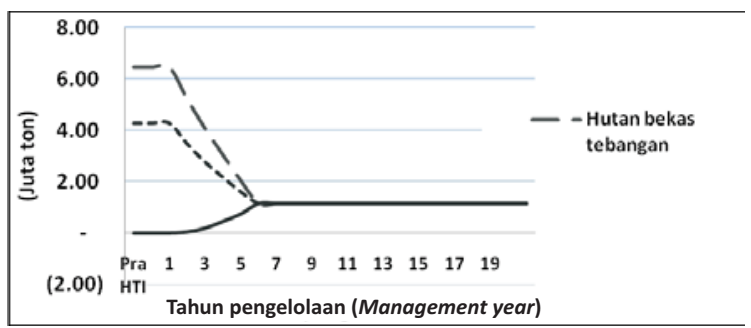

Gambar(Figure) 4. Kapasitas kandungan C dalam skala unit pengelolaan pada perubahan hutan rawa gambut menjadi HTI pulp (Capacity of carbon stock at management unit level on conversion of peatswamp forest towards pulpwood industrial plantation forests)

\section{B. Nilai Ekonomi Karbon HTI}

\section{Analisis Ekonomi Pengusahaan HTI Pulp Lahan Gambut}

Dalam rangka menjawab kepentingan kebijakan dan evaluasi keputusan pengelolaan HTI di lahan gambut, dilakukan studi dengan 
basis analisis ekonomi. Basis analisis yang digunakan antara lain : luas areal unit pengelolaan HTI 51.215 ha, jangka waktu analisis 20 tahun dengan daur tebang 5 tahun, pengusahaan HTI dengan modal sendiri dan tingkat suku bunga nyata sebesar $6,28 \%$.

Skenario pembangunan HTI dilakukan pada areal hutan alam terdegradasi. Investasi yang ditanamkan dimulai dari perencanaan kegiatan, pembangunan infrastruktur, pembangunan jalan dan kanal. Biaya operasional kegiatan pengelolaan HTI meliputi: biaya administrasi dan personil, pemeliharaan infrastruktur, penanaman, pemeliharaan tegakan, perlindungan dan pemanenan. Hasil analisis ekonomi pengusahaan HTI menggambarkan bahwa pengusahaan HTI di lahan gambut adalah layak sepanjang tingkat suku bunga riil tidak sama atau melebihi $14,79 \%$.

HTI pulp di hutan gambut terdegradasi mampu meningkatkan kandungan $\mathrm{C}$ vegetasi sehingga dapat menekan emisi untuk satuan wilayah tertentu. Oleh karena itu HTI pulp dapat berpartisipasi dalam proyek REDD. Aktivitas tersebut dapat dikategorikan sebagai Usaha Pemanfaatan Penyerapan Karbon (UP RAPKARBON) (Permenhut No. P.30/MenhutII/2009 dan Permenhut No. P.36/MenhutII/2009).

Partisipasi HTI pulp pada proyek REDD dapat meningkatkan NPV 20,21\% pada harga kompensasi US\$ 9,00/tCO ${ }_{2}$-e. Apabila harga satuan kompensasi dinaikkan menjadi US\$ $12,00 / \mathrm{tCO}_{2}-\mathrm{e}$, maka peningkatan NPV akan mencapai $51,13 \%$. Sedangkan pada harga kompensasi US\$ $6,00 / \mathrm{tCO}_{2}$-e tidak disarankan mengajukan kompensasi REDD, sebab perolehan NPV menjadi turun $10,7 \%$ (Tabel 1). Dengan demikian semakin besar nilai kompensasi akan berpotensi meningkatkan NPV. Analisis ini juga menemukan harga kompensasi minimal untuk proyek REDD pada HTI pulp sebesar US\$ 7,04 per $\mathrm{tCO}_{2}$-e, yang berasal dari biaya transaksi (transaction cost) proyek REDD.

Situasi di atas akan berubah apabila emisi $\mathrm{C}$ akibat subsidensi tanah diperhitungkan. Emisi akibat subsidensi tanah teridentifikasi 46,29 tC/ha/thn (Wahyunto et al., 2005), lebih kecil dari tambahan simpanan C HTI. Net emisi pada tahun ke-20 adalah 152,23 juta $\mathrm{tCO}_{2}$. Dengan demikian, intervensi REDD akan memberikan manfaat ekonomi lebih tinggi dibandingkan dengan konversi menjadi HTI pulp. Pada harga satuan kompensasi US\$ 6,00/tCO berpotensi menghasilkan NPV Rp 2,38 M.

Harga satuan kompensasi lebih dari US\$ 6,00/t $\mathrm{tCO}_{2}$-e memiliki peluang cukup baik. Gambaran mengenai pasar karbon global dikemukakan oleh Sheil et al. (2009) bahwa harga satuan karbon mulai dari US\$ 5,50 per ton di Chicago Climate Exchange (voluntary carbon market) hingga mencapai US\$ 30 per ton di European Compliance Market (untuk nilai April 2008). Hal demikian akan menjadikan komoditi ini sebagai suatu investasi menarik bagi pemerintah nasional suatu negara. Namun demikian, peluang tersebut juga ditentukan oleh kapasitas negosiasi Indonesia dalam mempromosikan REDD di hutan rawa gambut.

\section{Intervensi REDD pada Hutan Rawa Gambut}

\section{a. Pengalihan pencadangan HTI pulp menjadi UP PAN-KARBON dengan konservasi}

Hutan rawa gambut menjadi potensial dimasukkan ke dalam mekanisme REDD karena

Tabel (Table) 1. Resume hasil analisis ekonomi HTI pulp dengan dan tanpa REDD (Resume of economic analysis from pulpwood industrial plantation forest with and without REDD)

\begin{tabular}{|c|c|c|c|c|}
\hline \multirow{2}{*}{$\begin{array}{l}\text { Indikator } \\
\text { investasi } \\
\text { (Indicator } \\
\text { of investment) }\end{array}$} & \multirow{2}{*}{$\begin{array}{l}\text { HTI Murni } \\
\text { (Pure } \\
\text { industrial } \\
\text { plantation } \\
\text { forest) }\end{array}$} & \multicolumn{3}{|c|}{$\begin{array}{l}\text { HTI dengan REDD pada harga satuan kompensasi } \\
\text { (Industrial plantation forest with REDD at the base price of } \\
\text { compensation) }\end{array}$} \\
\hline & & US\$ $6.00 / \mathrm{tCO}_{2}-\mathrm{e}$ & US\$ 9.00/tCO 2 -e & $\mathrm{US} \$ 12.00 / \mathrm{tCO}_{2}$-e \\
\hline NPV/ha (Rp) & $15.561 .772,30$ & $13.896 .746,61$ & $18.707 .553,31$ & $23.518 .360,00$ \\
\hline $\mathrm{BCR}$ & 1,28 & 1,20 & 1,28 & 1,35 \\
\hline IRR & 14,79 & 14,47 & 15,28 & 15,84 \\
\hline
\end{tabular}


terjadinya defisit kandungan karbon pada perubahan hutan rawa gambut bekas tebangan dan sekunder menjadi HTI pulp. Melalui REDD, maka hutan rawa gambut dipertahankan dari konversi menjadi HTI pulp dengan memperoleh kompensasi tertentu. Penghindaran alih fungsi hutan alam gambut dihitung sebagai upaya mempertahankan simpanan karbon pada suatu lanskap. Skenario ini disebutkan dalam Peraturan Menteri Kehutanan No. P.36/Menhut-II/2009 sebagai kegiatan Usaha Pemanfatan Penyimpanan Karbon (UP PAN-KARBON), dan dinyatakan pada pasal 2 bahwa UP PANKARBON merupakan salah satu jenis usaha pemanfaatan jasa lingkungan pada hutan produksi dan hutan lindung. Kebijakan pemerintan menetapkan kawasan hutan produksi lahan gambut tertentu sebagai areal UP PANKARBON dapat disebut sebagai intervensi REDD pada hutan tersebut.

Intervensi REDD mampu menahan emisi sebesar 19,44 juta $\mathrm{tCO}_{2}$-e pada hutan alam bekas tebangan dan 11,46 juta $\mathrm{tCO}_{2}$-e pada hutan sekunder. Intervensi REDD pada hutan alam bekas tebangan memerlukan biaya US\$ $6,85 / \mathrm{tCO}_{2}-\mathrm{e}$, yang terdiri atas : biaya oportunitas US\$ 4,17/tCO ${ }_{2}-\mathrm{e}$, dan biaya transaksi US\$ 2,69/t $\mathrm{CO}_{2}$-e. Adapun intervensi REDD pada hutan sekunder memerlukan biaya yang lebih tinggi yaitu US\$ $11,63 / \mathrm{tCO}_{2}-\mathrm{e}$, yang terdiri atas : biaya oportunitas US\$ 7,07/tCO transaksi US\$ 4,56/tCO REDD ini berbeda pada setiap kondisi hutan, sebab berhubungan dengan tingkat emisi yang dihasilkan. Semakin tinggi emisi menunjukkan kecenderungan semakin rendah biaya oportunitasnya.

Analisis ekonomi pada hutan gambut bekas tebangan menunjukkan bahwa partisipasi konservasi hutan alam gambut bekas tebangan pada proyek REDD layak diajukan pada harga US\$ 9,00 dan $12,00 / \mathrm{tCO}_{2}$-e, sementara pada harga US\$ $6,00 / \mathrm{tCO}_{2}$-e tidak layak dilakukan. Harga titik impas untuk kompensasi REDD hutan bekas tebangan terbentuk pada US\$6,85/tCO Sedangkan analisis ekonomi REDD pada hutan gambut sekunder menghasilkan kelayakan proyek REDD pada harga US\$ $12,00 / \mathrm{tCO}_{2}$-e. Pada harga US\$ 9,00 dan $6,00 / \mathrm{tCO}_{2}$-e proyek REDD tidak layak untuk diikuti. Harga break event point terbentuk pada US\$11,63/ $\mathrm{tCO}_{2}$-e.

\section{b. Pengalihan pencadangan HTI pulp menjadiUPPAN-KARBONdengan PHPL}

Kemampuan menahan kehilangan simpanan karbon pada intervensi REDD melalui PHPL lebih rendah dari pada REDD konservasi. PHPL adalah Pengelolaan Hutan Produksi Lestari, sistem pengelolaan yang melakukan penebangan sebesar ${ }^{1} / 35$ dari potensi volume atau luas areal dan besarnya tebangan tidak melebihi

Tabel (Table) 2. Resume hasil analisis ekonomi skenario REDD dengan konservasi (Resume of economic analysis from REDD with conservation scenario)

\begin{tabular}{|c|c|c|c|c|c|}
\hline \multirow{2}{*}{ No. } & \multirow{2}{*}{$\begin{array}{c}\text { Indikator investasi } \\
\text { (Indicator of } \\
\text { investment ) }\end{array}$} & \multirow{2}{*}{$\begin{array}{l}\text { HTI Murni } \\
\text { (Pure } \\
\text { industrial } \\
\text { plantation } \\
\text { forest) }\end{array}$} & \multicolumn{3}{|c|}{$\begin{array}{l}\text { Intervensi REDD pada harga satuan kompensasi } \\
\text { (REDD intervention at the base price of compensation) }\end{array}$} \\
\hline & & & $\begin{array}{l}\mathrm{US} \$ \\
6.00 / \mathrm{tCO} 2-\mathrm{e}\end{array}$ & US\$ $9.00 / \mathrm{tCO}_{2}-\mathrm{e}$ & $\begin{array}{c}\text { US\$ } \\
12.00 / \text { tCO } 2-\mathrm{e}\end{array}$ \\
\hline A. & Hutan bekas tebangan & & & & \\
\hline 1. & NPV (Rp) & $797,00 \mathrm{M}$ & $-322,29 \mathrm{M}$ & $813,11 \mathrm{M}$ & $1,95 \mathrm{~T}$ \\
\hline 2. & NPV/ha (Rp) & $15.561 .772,30$ & $-6.292 .945,87$ & $15.876 .354,00$ & $38.045 .653,88$ \\
\hline 3. & $\mathrm{BCR}$ & 1,28 & 0,88 & 1,31 & 1,75 \\
\hline B. & Hutan sekunder & & & & \\
\hline 1. & NPV (Rp) & $797,00 \mathrm{M}$ & $-1,25 \mathrm{~T}$ & $-585,60 \mathrm{M}$ & $83,57 \mathrm{M}$ \\
\hline 2. & NPV/ha (Rp) & $15.561 .772,30$ & $-24.499 .893,16$ & $-11.434 .066,94$ & $1.631 .759,28$ \\
\hline 3. & $\mathrm{BCR}$ & 1,28 & 0,52 & 0,77 & 1,03 \\
\hline
\end{tabular}

Keterangan (Remarks) : M = milyar(billion)

$\mathrm{T}=\operatorname{trilyun}($ triliun $)$ 
riap tegakan. PHPL pada hutan bekas tebangan menyebabkan penurunan simpanan $\mathrm{C}$ dari 6,45 juta ton menjadi 4,61 juta ton (tahun ke-20). Pada hutan sekunder, penurunan simpanan $\mathrm{C}$ terjadi dari 4,28 juta ton menjadi 3,50 juta ton pada tahun ke-20. Dengan menggunakan HTI sebagai baseline, PHPL pada hutan gambut bekas tebangan mampu menahan emisi sebesar 17,26 juta $\mathrm{tCO}_{2-}$ e pada tahun kelima dan 12,70 juta $\mathrm{tCO}_{2}$ e pada tahun ke-20. Sedangkan PHPL pada hutan gambut sekunder dapat menurunkan emisi

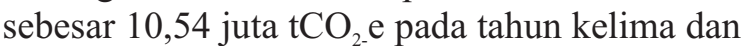
8,62 juta $\mathrm{tCO}_{2-}$ e pada tahun ke-20.

Skenario REDD-PHPL menghasilkan manfaat ekonomi lebih besar dibanding skenario REDD-konservasi. Mulai harga kompensasi US\$ $6,00 / \mathrm{tCO}_{2}$-e NPV sudah positif dengan $\mathrm{BCR}>1$. Skenario REDD-PHPL lebih fleksibel terhadap harga kompensasi. Kondisi demikian terjadi akibat adanya kontribusi penerimaan dari penjualan kayu hutan. Proyek REDD-PHPL tidak disarankan untuk diajukan pada harga < US\$ $6,00 / \mathrm{tCO}_{2}$-e (hutan bekas tebangan), atau harga $<$ US\$ 9,00/ $\mathrm{tCO}_{2}$-e (untuk hutan sekunder) Pada harga kompensasi tersebut diperoleh NPV dan BCR yang lebih kecil daripada pengusahaan HTI pulp. Harga minimal yang disarankan untuk proyek REDD adalah US\$ 7,61/tCO $\mathrm{CO}_{2}$-e (untuk UP PAN-KARBON-konservasi) dan US\$ 9,5/tCO ${ }_{2}$-e (untuk UP PAN-KARBON-PHPL).

\section{c. Pengalihan pencadangan HTI pulp dengan memperhitungkan kayu alam}

Apabila kayu alam diperhitungkan sebagai tambahan penerimaan investor, maka hal ini dapat menjadi daya tarik investor untuk menjadikan hutan alam bekas tebangan dan sekunder sebagai alokasi HTI pulp. Di lokasi penelitian potensi kayu komersil dapat diperoleh $109,17 \mathrm{~m}^{3}$ untuk hutan bekas tebangan dan 63,89 $\mathrm{m}^{3}$ untuk hutan sekunder.

Tambahan hasil kayu alam menjadi faktor utama penyebab meningkatnya penerimaan ekonomi sehingga NPV per ha dari Rp 15,6 juta menjadi Rp 296,73 juta untuk hutan bekas tebangan dan $\mathrm{Rp} 146,23$ juta untuk hutan sekunder. BCR juga meningkat dari 1,28 menjadi 5,23 dan 3,27 masing-masing untuk hutan bekas tebangan dan hutan sekunder. Tingginya penerimaan ekonomi akan menyebabkan terjadinya pembentukan harga satuan kompensasi minimal yang tinggi juga, sehingga harga kompensasi minimum untuk hutan bekas tebangan menjadi US\$ $130,64 / \mathrm{tCO}_{2}$-e dan untuk hutan sekunder US\$ $109,24 / \mathrm{tCO}_{2}$-e. Hal ini merupakan tantangan besar pemerintah untuk meyakinkan negara-negara donor bahwa hutan alam gambut Indonesia memiliki nilai karbon yang tinggi.

\section{Implikasi untuk Kebijakan Pengelolaan Hutan Rawa Gambut}

Kuantifikasi emisi dan simpanan karbon pada pengusahaan HTI pulp lahan gambut memberikan pengaruh cukup tinggi terhadap kalkulasi ekonomi dan pilihan kebijakan yang dapat diambil. Setidaknya hasil kuantifikasi emisi dan simpanan karbon menunjukkan beberapa situasi yang dapat dipilih secara selektif sebelum suatu lanskap hutan rawa gambut ditentukan alokasi penggunaan lahannya.

Tabel (Table) 3. Resume hasil analisis ekonomi REDD dengan PHPL (Resume of economic analysis from REDD with preservation logging scenario)

\begin{tabular}{|c|c|c|c|c|c|}
\hline \multirow{2}{*}{ No. } & \multirow{2}{*}{$\begin{array}{l}\text { Indikator } \\
\text { Investasi } \\
\text { (Indicator of } \\
\text { investment) }\end{array}$} & \multirow{2}{*}{$\begin{array}{c}\text { HTI Murni } \\
\text { (Pure industrial } \\
\text { plantation forest) }\end{array}$} & \multicolumn{3}{|c|}{$\begin{array}{l}\text { REDD dengan PHPL pada harga kompensasi } \\
\text { (REDD with PHPL at compensation price) }\end{array}$} \\
\hline & & & US\$ 6.00 & US\$ 9.00 & US\$ 12.00 \\
\hline A. & Hutan bekas tebangan & & & & \\
\hline 1. & NPV (Rp/ha) & 15561772.30 & 6183565.09 & 23729426.41 & 35749187.46 \\
\hline 2. & $\mathrm{BCR}$ & 1.28 & 1.12 & 1.47 & 1.70 \\
\hline 3. & IRR (\%) & 14.79 & 24.17 & 20.46 & 19.81 \\
\hline B. & Hutan sekunder & & & & \\
\hline 1. & NPV (Rp/ha) & 15561772.30 & 2604547.24 & 13725780.52 & 24847013.80 \\
\hline 2. & $\mathrm{BCR}$ & 1.28 & 1.09 & 1.46 & 1.84 \\
\hline 3. & $\operatorname{IRR}(\%)$ & 14.79 & 26.30 & 20.21 & 19.78 \\
\hline
\end{tabular}


Konversi hutan alam gambut menjadi HTI pulp dapat dipertimbangkan melalui beberapa karakteristik antara lain kondisi hutan, subsidensi tanah dan harga satuan kompensasi minimum. Semakin tinggi potensi hutan menunjukkan semakin tinggi simpanan karbon vegetasi, dan semakin tidak disarankan untuk dilakukan konversi. Semakin besar resiko subsidensi tanah semakin besar emisi yang terjadi dari karbon tanah, sehingga makin tidak disarakan untuk dilakukan konversi.

Pertimbangan harga kompensasi REDD juga merupakan faktor krusial lainnya agar pilihan kebijakan memenuhi profitabilitas yang memadai secara ekonomi. Hal ini sejalan dengan pendapat Dewi dan Budidarsono (2009) yang menyatakan bahwa keikutsertaan dalam proyek REDD perlu memperhitungkan dan mengidentifikasi bagian dari aktivitas ekonomi yang menyebabkan emisi dari deforestasi dan degradasi realistik untuk dihindari. Ukuran penghindaran realistik adalah jika biaya oportunitas dari aktivitas ekonomi pada suatu lanskap tertentu kurang dari harga satuan emisi yang dikompensasikan.

Penelitian ini memberikan bukti empiris bahwa karbon sebagai jasa lingkungan memiliki nilai ekonomi yang layak dipertimbangkan. Namun demikian, agar preferensi kebijakan dapat lebih memandang nilai hutan secara komprehensif, maka diperlukan informasi nilai ekonomi jasa lingkungan lain dan nilai ekonomi hasil hutan bukan kayu, seperti : produksi ikan, nilai air, tanaman obat, tanaman hias, rotan, getah-getahan, ekowisata, satwa liar dan nilai biodiversitas.

Nilai ekonomi karbon ini dapat memberikan tambahan nilai ekonomi total (total economic value) suatu kawasan hutan. Nilai ekonomi total merupakan konsep untuk melakukan valuasi sumber daya hutan secara holistik sebagai akumulasi nilai guna langsung, nilai guna tidak langsung dan nilai non guna (Pearce \& Turner, 1990). Apabila nilai guna flora dan fauna (tidak termasuk jasa lingkungan) diasumsikan sebesar Rp. 4.444.024/ha (Bahruni et al., 2007), dan nilai karbon hutan rawa gambut sebesar Rp. 25.595.020/ha (berdasarkan harga kompensasi REDD minimum untuk hutan rawa gambut bekas tebangan dan sekunder), maka nilai karbon memberikan kontribusi 5,8 kali lebih besar dalam pembentukan nilai ekonomi total sumber daya hutan di Indonesia.

\section{KESIMPULAN DAN SARAN}

1. Perubahan kandungan $\mathrm{C}$ vegetasi pada konversi hutan alam gambut menjadi HTI pulp tergantung pada kondisi hutan alamnya. Konversi pada hutan gambut bekas tebangan dan sekunder menyebabkan penurunan kandungan karbon vegetasi masing-masing sebesar 103,53 ton/ha/th dan 61,02 ton/ha/th. Sedangkan konversi pada hutan gambut terdegradasi menyebabkan terjadinya peningkatan kandungan karbon vegetasi sebesar 22,47 ton $/$ ha/th.

2. Nilai ekonomi HTI pulp diperoleh sebesar Rp 15,6 juta/ha. Adapun nilai ekonomi karbon vegetasi berbeda untuk setiap kondisi hutan rawa gambut, yaitu :

a. Partisipasi pengelolaan HTI pulp (yang dibangun pada hutan gambut terdegradasi) dalam proyek REDD (UP RAPKARBON) menyebabkan peningkatan nilai ekonomi sebesar 20,21\% dan 51,13\% untuk harga satuan kompensasi US\$ 9,00 dan $12,00 / \mathrm{tCO}_{2}$-e.

b. Hutan gambut sekunder yang diikutsertakan pada proyek REDD memiliki nilai ekonomi yang lebih kecil pada semua harga kompensasi yang disimulasikan dibanding dengan nilai ekonomi HTI pulp pada skenario UP PANKARBON konservasi. Sedangkan pada skenario UP PAN-KARBON dengan PHPL diperoleh nilai ekonomi yang lebih baik dibandingkan HTI pulp pada harga kompensasi US\$12,00/tCO

c. Hutan gambut bekas tebangan yang diikutsertakan pada proyek REDD memiliki nilai ekonomi yang lebih tinggi dari nilai ekonomi HTI pulp pada harga satuan kompensasi US\$ 9,00/tCO US\$ $12,00 / \mathrm{tCO}_{2}$-e pada skenario UP PANKARBON dengan konservasi maupun PHPL.

d. Apabila nilai kayu hutan alam dihitung sebagai tambahan penerimaan pada konversi hutan alam menjadi HTI pulp, maka harga satuan kompensasi minimal agar proyek REDD memberikan nilai ekonomi lebih tinggi dari HTI pulp adalah US\$ 130,64/ $\mathrm{tCO}_{2}$-e untuk hutan gambut bekas tebangan dan US\$109,24/ $\mathrm{tCO}_{2}$-e untuk hutan gambut sekunder. 
3. Apabila pasar karbon/REDD berjalan dengan sempurna, pembangunan HTI di lahan gambut terdegradasi dapat diikutsertakan dalam proyek REDD melalui UP RAPKARBON. Upaya mitigasi perubahan iklim melalui UP PAN-KARBON konservasi maupun PHPL dapat dikonsentrasikan pada hutan gambut bekas tebangan dan sekunder .

4. Agar nilai ekonomi REDD lebih tinggi dari HTI pulp, maka keputusan untuk mengikuti proyek REDD perlu mempertimbangkan harga satuan kompensasi minimal, yaitu :

a. Untuk HTI pulp dari hutan gambut terdegradasi sebesar US\$ 7,04/tCO (pada UPRAP-KARBON),

b. Untuk hutan gambut bekas tebangan sebesar US\$ 8,96/tCO ${ }_{2}$-e (pada UP PANKARBON konservasi) dan US\$ $7,61 / \mathrm{tCO}_{2}$-e (pada UP PAN-KARBON PHPL).

c. Untuk hutan sekunder sebesar US\$ $15,20 / \mathrm{tCO}_{2}$-e (pada UP PAN-KARBON konservasi) dan US\$ 9,5/ton $\mathrm{CO}_{2}$-e (pada UPPAN-KARBON PHPL).

5. Nilai ekonomi karbon merupakan salah satu nilai jasa lingkungan yang dapat dijadikan kriteria untuk pengambilan keputusan. Oleh karena itu, agar pertimbangan kebijakan menjadi lebih komprehensif, sebaiknya pertimbangan nilai ekonomi lingkungan lainnya dimasukkan sebagai kriteria pengambilan keputusan.

\section{DAFTAR PUSTAKA}

Agus, F., Suyanto, Wahyunto, and Noordwijk M van. 2007. Reducing emissions from peatland deforestation and degradation : carbon emission and opportunity costs. International symposium and workshop on tropical peatland. Carbon-climatehuman interaction- carbon pool, fire, mitigation, restoration and wise use. Yogyakarta, Indonesia, 27-31 August 2007.

Anshari, G.Z. and Armiyarsih. 2005. Carbon Decline from Peatlands and Its Implications on Livelihood Security of Local Communities. On Daniel Murdiyarso \& Hety Herawati, Editor. Carbon Forestry : Who Will Benefits.
Center for International Forestry Research. Bogor, Indonesia.

Bahruni, E. Suhendang, D. Darusman dan H.S. Alikodra. 2007. Pendekatan Sistem dalam Pendugaan Nilai Ekonomi Total Ekosistem Hutan : Nilai Guna Hasil Hutan Kayu dan Non Kayu. Jurnal Penelitian Sosial dan Ekonomi Kehutanan Vol. 4 No. 3 September 2007. Pusat Penelitian Sosial Ekonomi dan Kebijakan Kehutanan. Bogor.

Brown, S. 1994. Estimating biomass and biomass change in tropical forests, a primer. FAO Forestry Paper 134. Rome: FAO. http://www.fao.org/docrep/W4095E/ w4095e06.htm [18 Juli 2009].

Departemen Kehutanan. 2008. Eksekutif Data Strategis Kehutanan 2008. Departemen Kehutanan. Jakarta.

FAO (Food and Agricultur Organization). 2006. Global Forest Resources Assessment 2005 : Progress towards sustainable forest management. FAO Forestry Paper 147. FAO. FAO. Rome.

Hairiah, K. dan S. Rahayu. 2007. Pengukuran Karbon Tersimpan di Berbagai Macam Penggunaan Lahan. World Agroforestry Centre - ICRAF, SEA Regional Office, Universitas Brawijaya. Bogor, Indonesia.

Ginoga, K.L. dan M. Lugina. 2007. Biaya Transaksi dalam Perolehan Sertifikat Penurunan Emisi Mekanisme Pembangunan Bersih Kehutanan. Jurnal Penelitian Sosial dan Ekonomi Kehutanan Nomor 1 (4).

Hooijer, A., M. Silvius, H. Wösten and S. Page. 2006. PEAT-CO2 : Assessment of $\mathrm{CO}_{2}$ emission from drained peatlands in $S E$ Asia. Delft Hydraulics in corporation with Wetland International and Alterra Wageningen. Wageningen.

IPCC (International Panel on Climate Change). 2006. 2006 IPCC Guidelines for National Greenhouse Gas Inventories Volume 4: Agriculture, Forestry and Other Land Use. Prepared by the National Greenhouse Gas Inventories Programme, Eggleston H.S., Buendia L., Miwa K., Ngara T. and Tanabe K. (eds). IGES. Japan. 
Istomo. 2002. Kandungan Fosfor dan Kalsium serta Penyebarannya pada Tanah dan Tumbuhan Hutan Rawa Gambut (Studi kasus di wilayah Bagian Kesatuan Pemangkuan Hutan Bagan, Kabupaten Rokan Hilir, Riau). Disertasi (Tidak dipublikasikan). Sekolah Pascasarjana Institut Pertanian Bogor. Bogor.

Jaya, A., U.J. Siregar, H. Daryono, dan S. Suhartana. 2007. Biomasa Hutan Rawa Gambut Tropika pada Berbagai Kondisi Penutupan Lahan. Jurnal Penelitian Hutan dan Konservasi Alam No. 4 (4). Pusat Penelitian Hutan dan Konservasi Alam. Bogor.

Ministry of Forestry. 2008. IFCA 2007 Consolidation Report : Reducing Emission from Deforestation and Degradation in Indonesia.: FORDA (Forest Research and Development Agency). Jakarta, Indonesia.

Murdiyarso, D., U. Rosalina, K. Hairiah, L. Muslihat, I.N.N. Suryadiputra dan A. Jaya. 2004. Petunjuk Lapangan : Pendugaan Cadangan Karbon Lahan Gambut. Proyek Climate Change, Forests and Peatlands in Indonesia. Wetland International - Indonesia Programme and Wildlife Habitat Canada. Bogor, Indonesia.

Murray, B.C. 2004. Economics of Forest Carbon Sequestration. On Sills E.O. and K. Lee Abt, Editor. Forest in a Market Economy. Kluwer Academic Publishers. Dordrecht/ Boston/London.

Pearce, D.W., dan Turner R.K. 1990. Economic of Natural Resources and the Environment. Harvester Wheatsheaf. London.
Pirard, R. 2005. Pulpwood Plantations as Carbon Sinks in Indonesia: Methodological challenge and impact on livelihoods. On Murdiyarso, D. and Herawati H, Edtor. Carbon Forestry : Who Will Benefit? Proceedings of Workshop on Carbon Sequestration and Sustainable Livelihoods. Center for International Forestry Research. Bogor, Indonesia.

Rahmat, M., A. Sumadi, dan A.B. Hidayat. 2007a. Pendugaan Serapan Karbon Hutan Tanaman Acacia crassicarpa pada Lahan Gambut. Laporan Hasil Penelitian Balai Penelitian Kehutanan Palembang. Palembang: Balai Penelitian Kehutanan.

Rahmat, M., A. Sumadi, dan A.B. Hidayat. 2007b. Pendugaan Serapan Karbon Hutan Tanaman Acacia crassicarpa umur 2 dan 3 tahun di HTI PT. SBA Wood Industries. Prosiding Workshop Sintesa Hasil Litbang Hutan Tanaman. Tanggal 14 Desember 2007. Pusat Penelitian dan Pengembangan Hutan Tanaman. Bogor. [239-245]

Sheil, D., A. Casson, E. Meijaard, M. van Noordwijk, J. Gaskell, J. SunderlandGroves, K. Wertz and M. Kanninen. 2009. The Impact and Opportunities of Oil Palm in Southeast Asia: What do we know and what do we need to know. Occasional paper No. 51. Center for International Forestry Research. Bogor. Indonesia.

Wahyunto, S. Ritung, Suparto dan Subagjo. 2005. Sebaran Gambut dan Kandungan Karbon di Sumatera dan Kalimantan 2004. Wetland International Indonesia Programme. Bogor, Indonesia. 
Lampiran (Annex) 1. Sebaran jumlah pohon, biomasa dan kandungan karbon vegetasi pada hutan alam gambut bekas tebangan dan sekunder (Distribution of number of trees, biomass and carbon content of vegetation over logged swamp forest and secondary forest)

\begin{tabular}{|c|c|c|c|c|r|r|}
\hline \multirow{2}{*}{$\mathrm{D}$} & \multicolumn{2}{|c|}{ Hutan bekas tebangan (Logged over forest) } & \multicolumn{3}{|c|}{ Hutan sekunder (Secondary forest) } \\
\cline { 2 - 7 }$(\mathrm{cm})$ & $\mathrm{N}$ & $\mathrm{W}($ ton) & $\mathrm{C}$ (ton) & $\mathrm{N}$ & $\mathrm{W}$ (ton) & \multicolumn{1}{c|}{ (ton) } \\
\hline $5-15$ & $1.106,67$ & 36,05 & 18,02 & 626,67 & 18,29 & 9,15 \\
$15-25$ & 206,67 & 37,89 & 18,95 & 220,00 & 36,46 & 18,23 \\
$25-35$ & 46,67 & 21,96 & 10,98 & 166,67 & 35,35 & 17,70 \\
$35-45$ & 10,00 & 9,28 & 4,64 & 33,33 & 31,09 & 15,55 \\
$45-55$ & 10,00 & 16,75 & 8,38 & 10,00 & 18,11 & 9,05 \\
$55-65$ & 3,33 & 8,36 & 4,18 & 3,33 & 9,08 & 4,54 \\
$65-75$ & 10,00 & 40,50 & 20,25 & - & - & - \\
$>75$ & 6,67 & 81,22 & 40,61 & 3,33 & 18,54 & 9,27 \\
\hline Total & $1.400,00$ & 251,99 & 126,01 & $1.063,33$ & 166,93 & 83,49 \\
\hline
\end{tabular}

Keterangan (Remarks) : N : jumlah pohon (number of trees); W : biomasa (biomass); C : kandungan karbon (carbon content)

Lampiran (Annex) 2. Sebaran jumlah pohon, rerata diameter, biomasa dan kandungan karbon pada Hutan Tanaman Industri (HTI) pulp jenis Acacia crassicarpa (Distribution of number of trees, average of diameter, biomass and carbon content in the Industrial Forest Plantation (HTI) of A. crassicarpa

\begin{tabular}{|c|c|c|c|c|c|c|}
\hline \multirow{2}{*}{$\begin{array}{l}\text { Tahun Tanam } \\
\text { (Year of } \\
\text { planting)/ } \\
\text { Umur (Age) } \\
\end{array}$} & \multirow{2}{*}{ Parameter } & \multicolumn{4}{|c|}{ Petak ukur (0.1 ha) (Measurement plots) } & \multirow{2}{*}{ Per ha } \\
\hline & & PU 1 & PU 2 & PU 3 & $\begin{array}{c}\text { Rerata } \\
\text { (Average) }\end{array}$ & \\
\hline \multirow{4}{*}{$\begin{array}{l}2008 / \\
1 \text { tahun }\end{array}$} & - Jumlah pohon/ha & 114,00 & 125,00 & 121,00 & 120,00 & $1.200,00$ \\
\hline & - Rerata dbh (cm) & 6,12 & 6,29 & 6,52 & 6,31 & 6,31 \\
\hline & - Biomasa (kg) & 774,59 & 964,92 & $1.012,12$ & 917,21 & $9.172,10$ \\
\hline & - Karbon (kg) & 387,29 & 482,46 & 506,06 & 458,61 & $4.586,05$ \\
\hline \multirow{4}{*}{$\begin{array}{l}2007 / \\
2 \text { tahun }\end{array}$} & - Jumlah pohon/ha & 121,00 & 109,00 & 108,00 & 112,67 & $1.126,67$ \\
\hline & - Rerata dbh (cm) & 10,29 & 9,98 & 10,30 & 10,19 & 10,19 \\
\hline & - Biomasa (kg) & $3.186,00$ & $2.632,24$ & $2.784,02$ & $2.867,42$ & $28.674,18$ \\
\hline & - Karbon (kg) & $1.593,00$ & $1.316,12$ & $1.392,01$ & $1.433,71$ & $14.337,09$ \\
\hline \multirow{4}{*}{$\begin{array}{l}2006 / \\
3 \text { tahun }\end{array}$} & - Jumlah pohon/ha & 63,00 & 62,00 & 61,00 & 62,00 & 620,00 \\
\hline & - Rerata dbh $(\mathrm{cm})$ & 15,21 & 14,74 & 16,18 & 15,37 & 15,37 \\
\hline & - Biomasa (kg) & 5204,59 & $4.613,05$ & $5.614,06$ & $5.143,90$ & $51.438,99$ \\
\hline & - Karbon (kg) & 2602,29 & $2.306,53$ & $2.807,03$ & $2.571,95$ & $25.719,49$ \\
\hline \multirow{4}{*}{$\begin{array}{l}2005 / \\
4 \text { tahun }\end{array}$} & - Jumlah pohon/ha & 57,00 & 60,00 & 72,00 & 63,00 & 630,00 \\
\hline & - Rerata dbh (cm) & 15,64 & 15,97 & 15,62 & 15,74 & 15,74 \\
\hline & - Biomasa (kg) & $4.871,18$ & $5.420,42$ & $6.614,93$ & $5.635,51$ & $56.355,11$ \\
\hline & - Karbon (kg) & $2.435,59$ & $2.710,21$ & $3.307,47$ & $2.817,76$ & $28.177,55$ \\
\hline \multirow{4}{*}{$\begin{array}{l}2004 / \\
5 \text { tahun }\end{array}$} & - Jumlah pohon/ha & 52,00 & 78,00 & 70,00 & 66,67 & 666,67 \\
\hline & - Rerata dbh (cm) & 17,42 & 15,65 & 17,46 & 16,84 & 16,84 \\
\hline & - Biomasa (kg) & $6.400,31$ & $8.689,64$ & $8.616,01$ & $7.901,99$ & $79.019,85$ \\
\hline & - Karbon (kg) & $3.200,15$ & $4.344,82$ & $4.308,00$ & $3.950,99$ & $39.509,93$ \\
\hline
\end{tabular}




\section{Lampiran (Annex) 3.}

\section{CONTOH PERHITUNGAN (Examples of Calculation)}

1. Biomasa Pohon di Hutan Rawa Gambut

a. Biomasa atas permukaan (Wag) dihitung dengan formula $\rightarrow$ Wag $=\rho 0,19 \mathrm{D}^{2,37}$

Jika diketahui diameter pohon (D) $=10,9$ $\mathrm{cm}$ dan berat jenis kayu 0,68 , maka

Wag $=0,68 * 0,19 * 10,9^{2.37}$

Wag $=36,83 \mathrm{~kg}$

b. Biomasa bawah permukaan (Wbg) dihitung dengan formula $\rightarrow \mathrm{Wbg}=$ 0,25 Wag

Jika diketahui Wag $=36,83 \mathrm{~kg}$, maka

$\mathrm{Wbg}=0,25 * 36,83$

$\mathrm{Wbg}=9,21 \mathrm{~kg}$

c. Total Biomasa pohon (W) dihitung dengan

$\mathrm{W}=\mathrm{Wag}+\mathrm{Wbg}$

$\mathrm{W}=36,83+9,21$

$\mathrm{W}=46,03 \mathrm{~kg}$

2. Biomasa Pohon HTI Acacia crassicarpa

Total biomasa pohon $A$. crassicarpa dihitung dengan formula $\rightarrow \mathrm{W}=0,0267 \mathrm{D}^{2,8912}$

Jika diketahui diameter pohon $(D)=13,7 \mathrm{~cm}$, maka

$\mathrm{W}=0,0267 * 13,7^{2,8912}$

$\mathrm{W}=51,58 \mathrm{~kg}$

3. Kandungan Karbon atau Karbon Tersimpan dalam Pohon
Formula perhitungan $\rightarrow \mathrm{C}=0,5 \mathrm{~W}$

Jika diketahui $\mathrm{W}=46,03 \mathrm{~kg}$, maka

$\mathrm{C}=0,5 * 46,03$

$\mathrm{C}=23,02 \mathrm{~kg}$

4. Estimasi Kandungan Karbon dalam Tegakan Estimasi kandungan karbon dalam tegakan (dalam satuan luas hutan tertentu) dihitung dengan mengalikan rataan kandungan karbon dari semua Petak Ukur (Cpu) dengan 10, karena luas petak ukur adalah 0.1 ha. Jika diketahui $\mathrm{Cpu}=1.894,83 \mathrm{~kg}$, maka

C perha $=1.894,83 * 10$

C per ha $=18.948,29 \mathrm{~kg} / \mathrm{ha}$ atau 18,95 ton $/ \mathrm{ha}$

5. Estimasi Perubahan Kandungan Karbon Dihitung dengan mencari perbedaan kandungan karbon sebelum konversi $\left(\mathrm{C}_{A}\right)$ dengan setelah konversi $\left(\mathrm{C}_{B}\right)$ dengan formula $\rightarrow \Delta \mathrm{C}_{L U i}=\mathrm{C}_{A}-\mathrm{C}_{B}$

Jika diketahui kandungan $\mathrm{C}$ sebelum konversi (hutan rawa gambut) $\left(\mathrm{C}_{A}\right)=6,45$ juta ton dan kandungan $\mathrm{C}$ setelah konversi (HTI) tahun ke$6\left(\mathrm{C}_{B}\right)=1,15$ juta ton, maka

$\Delta \mathrm{C}=6,45$ juta $-1,15$ juta

$\Delta \mathrm{C}=5,30$ juta ton

6. Estimasi $\mathrm{Co}_{2}$

Dihitung dengan formula $\rightarrow \mathrm{CO}_{2}=\mathrm{C} *(44 / 12)$

Jika diketahui emisi $\mathrm{C}=5,30$ juta ton, maka emisi dalam $\mathrm{CO}_{2}$ adalah

$\mathrm{CO}_{2}=5,30$ juta $*(44 / 12)$

$\mathrm{Co}_{2}=19,44$ juta ton 